\title{
Babinski Sign
}

National Cancer Institute

\section{Source}

National Cancer Institute. Babinski Sign. NCI Thesaurus. Code C43247.

A reflex characterized by upward movement of the great toe and an outward movement of the rest of the toes, when the sole of the foot is stroked. It is a normal reflex up to the age of two. Its presence beyond that age indicates neurological damage. 